\title{
ХАРАКТЕРИСТИКА ГЕНОТИПА И ФЕНОТИПА НЕТОКСИГЕННЫХ ШТАММОВ CORYNEВАCTERIUM DIPHTHERIAE SUBSP. LAUSANNENSE, ВЫДЕЛЕННЫХ НА ТЕРРИТОРИИ РОССИИ
}

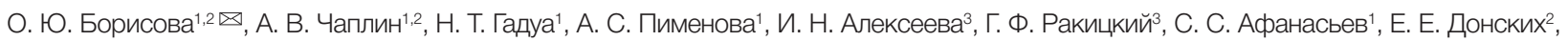
Л. И. Карарская²

${ }^{1}$ Московский научно-исследовательский институт эпидемиологии и микробиологии имени Г. Н. Габричевского, Москва, Россия

2 Российский национальный исследовательский медицинский университет имени Н. И. Пирогова, Москва, Россия

${ }^{3}$ Краевая клиническая психиатрическая больница, Хабаровск, Россия

В 2018 г. на основании полногеномных данных появились публикации о наличии двух монофилетических кластеров внутри вида C. diphtheriae, что позволяет дифференцировать этот вид на два подвида: C. diphtheriae subsp. diphtheriae и C. diphtheriae subsp. lausannense. Целью работы было описать генотип и фенотип двух нетоксигенных штаммов C. diphtheriae, выделенных в 2017-2018 гг. с профилактической целью, которые на основании совокупности результатов множества методов могут быть отнесены к C. diphtheriae subsp. lausannense. В исследовании использовали микробиологические и молекулярно-генетические методы, а также биоинформатический поиск подвид-специфичных генов в публично доступных геномах C. diphtheriae. Выделенные штаммы имели характерные для C. diphtheriae морфо-культуральные свойства и биохимическую характеристику. В МЛСТ штаммы принадлежали к сиквенс-типу ST199, входящему в клональный комплекс, ассоциированный с subsp. lausannense. C использованием ПЦР были показаны наличие ptsl (гена, кодирующего фосфоенолпируват-белок фосфотрансферазы) и отсутствие пагG (гена, кодирующего синтез субъединиц нитратредуктазы) у двух исследуемых штаммов C. diphtheriae subsp. lausannense и противоположная картина - у штаммов C. diphtheriae subsp. diphtheriae. Была экспериментально подтверждена способность выделенных штаммов подвида lausannепsе сбраживать N-ацетилглюкозамин. Полученные результаты расширяют представления о биологическом разнообразии вида C. diphtheriae и свидетельствуют о необходимости дальнейших исследований по оценке распространенности этих микроорганизмов и изучению их патогенного потенциала.

Ключевые слова: дифтерия, нетоксигенные Corynebacterium diphtheriae, Corynebacterium diphtheriae subsp. lausannense, мультилокусное секвенирование, филогенетический анализ

Вклад авторов: О. Ю. Борисова - молекулярно-генетические исследования, анализ данных, анализ литературы, подготовка рукописи; А. В. Чаплин филогенетический анализ, анализ данных, подготовка рукописи; Н. Т. Гадуа и А. С. Пименова - микробиологические исследования, подготовка рукописи; И. Н. Алексеева и Г. Ф. Ракицкий - обследование пациентов и первичная идентификация, подготовка рукописи; С. С. Афанасьев молекулярно-генетические исследования, подготовка рукописи; Е. Е. Донских - анализ данных, анализ литературы, подготовка рукописи; Л. И. Кафарская - анализ данных, подготовка рукописи.

Соблюдение этических стандартов: исследование одобрено этическим комитетом Московского научно-исследовательского института эпидемиологии и микробиологии имени Г. Н. Габричевского. Все пациентки подписали добровольное инсормированное согласие на участие в исследовании.

$\triangle$ Для корреспонденции: Ольга Юрьевна Борисова ул. Адмирала Макарова, д. 10, г. Москва, 125212; olgborisova@mail.ru

Статья получена: 09.02.2020 Статья принята к печати: 28.02.2020 Опубликована онлайн: 18.03 .2020

DOI: $10.24075 /$ vrgmu.2020.015

\section{CHARACTERIZATION OF THE GENOTYPE AND THE PHENOTYPE OF NONTOXIGENIC STRAINS OF CORYNEBACTERIUM DIPHTHERIAE SUBSP. LAUSANNENSE ISOLATED IN RUSSIAN RESIDENTS}

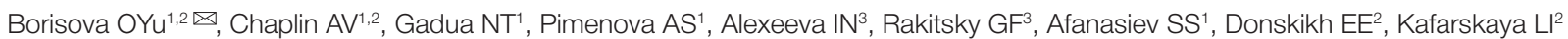

${ }^{1}$ G. N. Gabrichevsky Research Institute for Epidemiology and Microbiology, Moscow, Russia

2 Pirogov Russian National Research Medical University, Moscow, Russia

${ }^{3}$ Regional Clinical Psychiatric Hospital, Khabarovsk, Russia

In 2018, a few sequencing studies were published revealing the existence of two monophyletic clusters within the C. diphtheriae species, meaning that this species can be divided into two subspecies: C. diphtheriae subsp. diphtheriae and C. diphtheriae subsp. lausannense. The objective of our study was to describe the genotype and the phenotype of 2 nontoxigenic C. diphtheriae strains isolated in Russia in 2017-2018, which were classified by us as C. diphtheriae subsp. lausannense based on the aggregated data yielded by a variety of techniques, including microbiological and molecular genetic techniques, as well as a bioinformatic search for subspecies-specific genes in the publicly available genomes of $C$. diphtheriae. The isolated strains had morphological and biochemical characteristics of C. diphtheriae. The strains were assigned to the MLST type ST199 included in the clonal complex associated with subsp. lausannense. PCR revealed that both analyzed strains of $C$. diphtheriae subsp. lausannense carried the ptsl gene encoding phosphoenolpyruvate-protein phosphotransferase and did not carry the narG gene encoding the synthesis of nitrate reductase subunits, whereas the strains of $C$. diphtheriae subsp. diphtheriae had the narG gene and did not have ptsl. We experimentally proved the ability of lausannense strains to ferment $\mathrm{N}$-acetylglucosamine. Our findings expand the knowledge of the biological diversity of C. diphtheriae and indicate the need for estimating the spread of these microorganisms in Russia, as well as their pathogenic potential.

Keywords: diphtheria, nontoxigenic Corynebacterium diphtheriae, Corynebacterium diphtheriae subsp. lausannense, multilocus sequence typing, phylogenetic analysis

Author contribution: Borisova OYu carried out molecular genetic tests, analyzed the literature and the obtained data, contributed to manuscript preparation; Chaplin AV performed phylogenetic analysis, analyzed the experimental data and contributed to manuscript preparation; Gadua NT, Pimenova AS carried out microbiological tests and contributed to manuscript preparation; Alexeeva IN, Rakitsky GF examined the patients on admission and contributed to manuscrip preparation; Afanasiev SS conducted molecular genetic tests and contributed to manuscript preparation; Donskikh EE analyzed the literature and the experimental data and contributed to manuscript preparation; Kafarskaya LI analyzed the experimental data and contributed to manuscript preparation.

Compliance with ethical standards: the study was approved by the Ethics Committee of G. N. Gabrichevsky Research Institute for Epidemiology and Microbiology. Informed consent was obtained from all participants.

Correspondence should be addressed: Olga Yu. Borisova

Admirala Makarova, 10, Moscow, 125212; olgborisova@mail.ru

Received: 09.02.2020 Accepted: 28.02.2020 Published online: 18.03.2020

DOI: 10.24075/brsmu.2020.015 
Возбудителем дифтерии являются токсигенные штаммы Corynebacterium diphtheriae, в геном которых интегрирована ДНК бактериофага, содержащая ген токсина. Передача возбудителя происходит, как правило, воздушно-капельным путем от человека к человеку с развитием классической дифтерии зева и/или носа.

Благодаря программам массовой иммунизации заболеваемость дифтерией в мире за последнее столетие резко снизилась [1]. В России в настоящее время в условиях поддержания высокого уровня привитости (95\% и более) достигнута стабилизация заболеваемости [2]. В 2017 г. случаи заболевания дифтерией не регистрировали, выявлено два случая бактерионосительства; в 2018 г. зарегистрировано четыре случая заболевания и три случая бактерионосительства; за 9 месяцев 2019 г. - три случая заболевания и два случая бактерионосительства [3]. При этом за последние годы не было зарегистрировано как вторичных случаев в очагах, так и летальных исходов. В структуре клинических форм преобладают легкие локализованные формы дифтерии.

Однако актуальность проблемы дистерийной инфекции в условиях единичных случаев заболеваний по сей день сохраняется, так как утрачивается опыт клинического и бактериологического распознавания дифтерии; сохраняется резервуар возбудителя в форме бактерионосительства; эпидемический процесс протекает среди привитого населения [3].

В последнее время можно наблюдать рост инфекций, вызванных нетоксигенными штаммами C. diphtheriae, с атипичными клиническими проявлениями, включая фарингит, инфекции дыхательных путей, эндокардит, остеомиелит, септический артрит или кожные инфекции [4-8].

На основе биохимического фенотипического тестирования C. diphtheriae исторически классисицировали на четыре биовара: gravis, mitis, intermedius и belfanti [9, 10]. Однако штаммы C. diphtheriae в пределах определенного биовара могут быть генетически более отдаленными $[11,12]$. Поэтому геномика не поддерживает использование биоваров для надежной классификации штаммов C. diphtheriae [13]. Кроме того, отсутствует корреляция между определением биовара и патогенностью [14]. Мультилокусное сиквенс-типирование (MLST), основанное на аллельном определении семи генов «домашнего хозяйства", позволило разделить существующее разнообразие штаммов на две эволюционные линии: lineage-1 (включает в себя большинство штаммов) и lineage-2 (включает только штаммы биовара belfanti) [14].

В 2018 г. появилась публикация об описании трех нетоксигенных штаммов C. diphtheriae [15]. Один из них был выделен в Швейцарии от пациента с трахеобронхитом с множественными поражениями дистальной трахеи и главных бронхов, два других штамма - из мазков из носа и зева от пациентов в Великобритании и Индии. Сравнительные геномные исследования с общедоступными геномами C. diphtheriae показали, что выделенные штаммы имеют более низкую среднюю идентичность нуклеотидов (от 95,24 до 95,39\%) с эталонным геномом C. diphtheriae NCTC 11397, чем остальные ранее опубликованные геномы C. diphtheriae (> 98,15\%). Реконструкция филогении на основании полногеномных данных подтвердила наличие двух монофилетических кластеров внутри вида, соответствующих lineage-1 и lineage-2. На основании этих результатов было предложено классифицировать вид C. diphtheriae на два подвида: C. diphtheriae subsp. diphtheriae и C. diphtheriae subsp. lausannense.
Цель данного исследования - описать генотип и фенотип нетоксигенных штаммов C. diphtheriae, выделенных в 2017-2018 гг., которые на основании совокупности множества методов можно отнести к C. diphtheriae subsp. lausannense.

\section{МАТЕРИАЛЫ И МЕТОДЬ}

В экспериментальную часть исследования было включено два нетоксигенных штамма C. diphtheriae, выделенных в период 2017-2018 гг. в бактериологической лаборатории Краевой клинической психиатрической больницы г. Хабаровска; контрольный токсигенный штамм C. diphtheriae биовара gravis № 665 (из Государственной коллекции патогенных микроорганизмов «ГКПМ-Оболенск»), а также свежевыделенные токсигенные штаммы C. diphtheriae № 66-19, 98-19 (биовара gravis), № 55-19, № 56-19 (биовара mitis); нетоксигенные штаммы C. diphtheriae № 57-19, 67-19 (биовара gravis), № 60-19, № 91-19 (биовара mitis), присланные в Ресреренс-центр по мониторингу возбудителей кори, краснухи, эпидемического паротита, коклюша и дифтерии Московского научноисследовательского института эпидемиологии и микробиологии имени Г. Н. Габричевского из субъектов РФ.

Изучение штаммов C. diphtheriae проводили согласно МУ 4.2.3065-13 «Лабораторная диагностика дифтерийной инфекции". Исследуемый материал засевали на кровянотеллуритовую среду (КТА) на основе 2\%-го агара (ГРМагар, ГНЦПМБ; Оболенск, Россия) с добавлением 7\% крови крупного рогатого скота («Лейтран»; Россия) и теллурита калия (ГНЦПМБ; Оболенск, Россия) и термостатировали в течение 24-48 ч при температуре $3{ }^{\circ} \mathrm{C}$. Выросшие колонии C. diphtheriae оценивали по культурально-морфологическим, токсигенным и биохимическим свойствам. Токсигенность штаммов C. diphtheriae оценивали в реакции преципитации в агаре с использованием питательного агара «Коринетоксагар» (ГНЦПМБ; Оболенск, Россия) с добавлением 20\% сыворотки крупного рогатого скота («Лейтран»; Россия) и дисков, пропитанных дифтерийным антитоксином («Диагностические системы», Нижний Новгород, Россия). Один диск с антитоксином содержал $5 \pm 1 \mathrm{ME}$ дифтерийного антитоксина (согласно МУК 4.2.3065-13). Биохимические свойства выделенных культур изучали по оценке цистиназной, уреазной, сахаролитической и нитратредуктазной активностей на средах, приготовленных в лабораторных условиях, а также с использованием биохимической тест-системы «ДС-ДИФ-КОРИНЕ» («Диагностические системы», Нижний Новгород, Россия).

Для определения возможности сбраживания $\mathrm{N}$-ацетилглюкозамина в основу Гисса ex temporo был добавлен $\mathrm{N}$-ацетилглюкозамин (Sigma-Adlrich; CША). Далее в приготовленный раствор объемом 3 мл внесли полную бактериологическую петлю суточных культур C. diphtheriae, выращенных на сывороточном агаре. Культуры инкубировали 24-48 ч при температуре $37^{\circ} \mathrm{C}$. Интерпретацию результатов проводили по изменению цвета раствора. Контролем служили два токсигенных штамма биовара gravis, два нетоксигенных штамма биовара gravis, два токсигенных штамма биовара mitis и два нетоксигенных штамма биовара mitis.

Для изучения опубликованных геномных последовательностей использовали 204 генома C. diphtheriae подвидов diphtheriae и lausannense, представленных в базе данных NCBI Refseq. Выборку дополнили тремя 
геномами C. diphtheriae subsp. lausannense из базы данных NCBI Genbank и одним геномом Corynebacterium ulcerans BR-AD22 в качестве внешнего представителя для филогенетической реконструкции. Итоговый объем выборки составил 208 геномов.

Белок-кодирующие области в геномах в соответствии с представленными в базах данных аннотациями кластеризовали в группы ортологов с использованием программного обеспечения OrthoMCL [16] со стандартными настройками (индекс инфляции составил 1.5, порог схожести белковых последовательностей - 50\%, порог e-value - 10-5). Для реконструкции филогении использовали группы ортологов, в которые входили гены, присутствовавшие во всех геномах в одной копии. Нуклеотидные последовательности выравнивали с использованием MUSCLE [17] и конкатенировали. Реконструкцию филогении осуществляли по алгоритму Maximum Likelihood, реализованному в программном обеспечении FastTree [18], с использованием модели GTR+CAT. Отношения опубликованных геномных последовательностей к сиквенс-типам по методу MLST предсказывали на основе данных из базы PubMLST. Формирование клональных комплексов производили с помощью алгоритма goeBURST на уровне SLV в программе Phyloviz 2.0 [19].

Тотальную ДНК выделяли стандартным методом кипячения из 24-часовой культуры C. diphtheriae, выращенной на ГРМ-агаре (ГНЦПМБ; Оболенск, Россия) с добавлением $10 \%$ крови крупного рогатого скота («Лейтран»; Москва) и последующим центрифугированием.

Фрагменты гена tox у нетоксигенных штаммов C. diphtheriae выявляли в соответствии с опубликованным протоколом [20]. Реакционная смесь для ПЦР содержала 1,5 $\mathrm{MM} \mathrm{MgCl}_{2}, 10 \mathrm{MM}$ Tris- $\mathrm{HCl}(\mathrm{pH} 8,3), 50 \mathrm{MM} \mathrm{KCl}, 0,1 \mathrm{MKM}$ прямого и обратного праймеров, 200 мМ каждого dNTP и 1 ед. Таq ДНК-полимеразы (Thermo Fisher Scientific; США). В качестве положительного контроля амплификации использовали ДНК контрольного токсигенного штамма C. diphtheriae биовара gravis № 665. Генотипирование штаммов C. diphtheriae с помощью МЛСТ проводили согласно международному протоколу [14] на основе секвенирования фрагментов семи генов «домашнего хозяйства» - atpA, dnaE, dnaK, fusA, leuA, odhA и rрoB. Секвенирование проводили согласно общепринятому методу Сенгера в ЗАО «Евроген» (Москва). Идентификацию аллелей осуществляли согласно международной базе данных PubMLST.

Таблица 1. Характеристика исследованных культур C. diphtheriae
ПЦР для выявления фрагментов гена $d t x R$ у штаммов C. diphtheriae проводили с использованием одной пары праймеров, охватывающей всю область гена $d t x R$ : GGGACTACAACGCAACAAGAA и TCATCTAATTTCGCCGCCTTTA согласно [20, 21]. Подвид-специфичную ПЦР проводили с праймерами pts/_F: ACTTTCCGAACCTGCCATCC и pts/_R: GTGTACTCCTTCGTCTGCTC. narG_F: CTGACCACTGGGGCGAGG и narG_R: GAGTTGTCATAACGCCACTG.

\section{РЕЗУЛЬТАТЫ ИССЛЕДОВАНИЯ}

Штаммы C. diphtheriae B-8759 и B-8760 были выделены из зева двух пациентов (26 и 77 лет), госпитализированных в различные отделения психиатрического стационара, которые были обследованы профилактически при поступлении с целью выявления бактерионосительства (согласно п. 3.4 Методических указаний 3.1.3018-12 «Эпидемиологический надзор за дифтерией»). Нами была проведена идентификация выделенных штаммов по культурально-морфологическим, токсигенным и биохимическим свойствам согласно Методическим указаниям 4.2.3065-13 «Лабораторная диагностика дифтерийной инфекции». На кровяно-теллуритовом агаре наблюдали серо-черные шероховатые колонии с легкой краевой исчерченностью, с приподнятым центром; при соприкосновении колонии крошились. Токсигенность определяли с помощью дисков, пропитанных дифтерийным антитоксином, по методу Фельдмана. У выделенных культур через 24 и 48 ч инкубации отсутствовали специфичные линии преципитации при наличии специфичных линий преципитации у контрольного токсигенного штамма C. diphtheriae биовара gravis № 665, что свидетельствовало об отсутствии у них токсигенности. Проведение ПЦР для выявления фрагмента гена tох показало, что у исследуемых штаммов ген дифтерийного токсина отсутствует.

Биохимические свойства выделенных культур изучали с оценкой цистиназной, уреазной, сахаролитической и нитратредуктазной активности. Так, выделенные культуры C. diphtheriae обладали цистиназной активностью с образованием «коричневого облака» по ходу укола в среду Пизу, ферментировали глюкозу, мальтозу, фруктозу и галактозу, не ферментировали сахарозу и крахмал, не обладали уреазной и нитратредуктазной активностью (табл. 1). В результате проведенной идентификации выделенные культуры были предварительно отнесены к C. diphtheriae биовар belfanti, что характерно для представителей подвида lausannense.

\begin{tabular}{|c|c|c|c|}
\hline \multirow{2}{*}{ Признак } & \multicolumn{3}{|c|}{ Штаммы C. diphtheriae } \\
\hline & № 665 (контроль) & B-8759 & B-8760 \\
\hline Сбраживание глюкозы & + & + & + \\
\hline Сбраживание сахарозы & - & - & - \\
\hline Сбраживание мальтозы & + & + & + \\
\hline Сбраживание фруктозы & + & + & + \\
\hline Сбраживание галактозы & + & + & + \\
\hline Сбраживание крахмала & + & - & - \\
\hline Уреаза & - & - & - \\
\hline Нитратредуктаза & + & - & - \\
\hline Проба Пизу & + & + & + \\
\hline Токсигенность (метод Фельдмана) & + & - & - \\
\hline Наличие гена tox & + & - & - \\
\hline
\end{tabular}


На следующем этапе работы было проведено исследование ранее опубликованных геномов C. diphtheriae с целью подтверждения четкого разделения данного вида на подвиды и поиска видоспецифичных белок-кодирующих генов.

Реконструкция филогенетического древа (рис. 1) подтвердила на большей выборке ранее полученные данные о том, что представители вида C. diphtheriae формируют две клады, соответствующие подвидам diphtheriae и lausannense. Она указала также на то, что представители данных подвидов относятся к непересекающимся группам сиквенс-типов. По результатам кластеризации описанных в PubMLST МЛСТ-типов с помощью goeBURST (рис. 2), все представители подвида lausannense с просеквенированным геномом имеют сиквенс-типы ST106, ST360, ST409, а также один неописанный тип, отличающийся одним аллелем от ST359, входящие в один клональный комплекс.

Можно предположить, что все остальные сиквенстипы (например, ST35, ST37, ST69, ST81), представленные в данном клональном комплексе, тоже относятся к lausannense. Дополнительным подтверждением тому может служить тот факт, что почти все изоляты из сиквенстипов данного клонального комплекса описаны в базе данных PubMLST как относящиеся к биовару belfanti, характерному для подвида lausannense.

Анализ групп ортологов показал существование локусов, специсичных для подвидов C. diphtheriae. Так, все штаммы подвида lausannense имели регион (вероятно, оперон), содержащий гены фосфотрансферазной системы, предполагаемым субстратом которой служит $\mathrm{N}$-ацетилглюкозамин. Под ген фосфоенолпируват-белка, кодирующего фосфотрансферазу, были подобраны праймеры: ptsI_F: ACTTTCCGAACCTGCCATCC и ptsI_R: GTGTACTCCTTCGTCTGCTC (ожидаемая длина продукта 489 пн). В то же время только среди геномов подвида diphtheriae был обнаружен локус, кодирующий синтез субъединиц нитратредуктазы. Под ген ее $\alpha$-субъединицы (присутствующий в геномной сборке 201 штамма

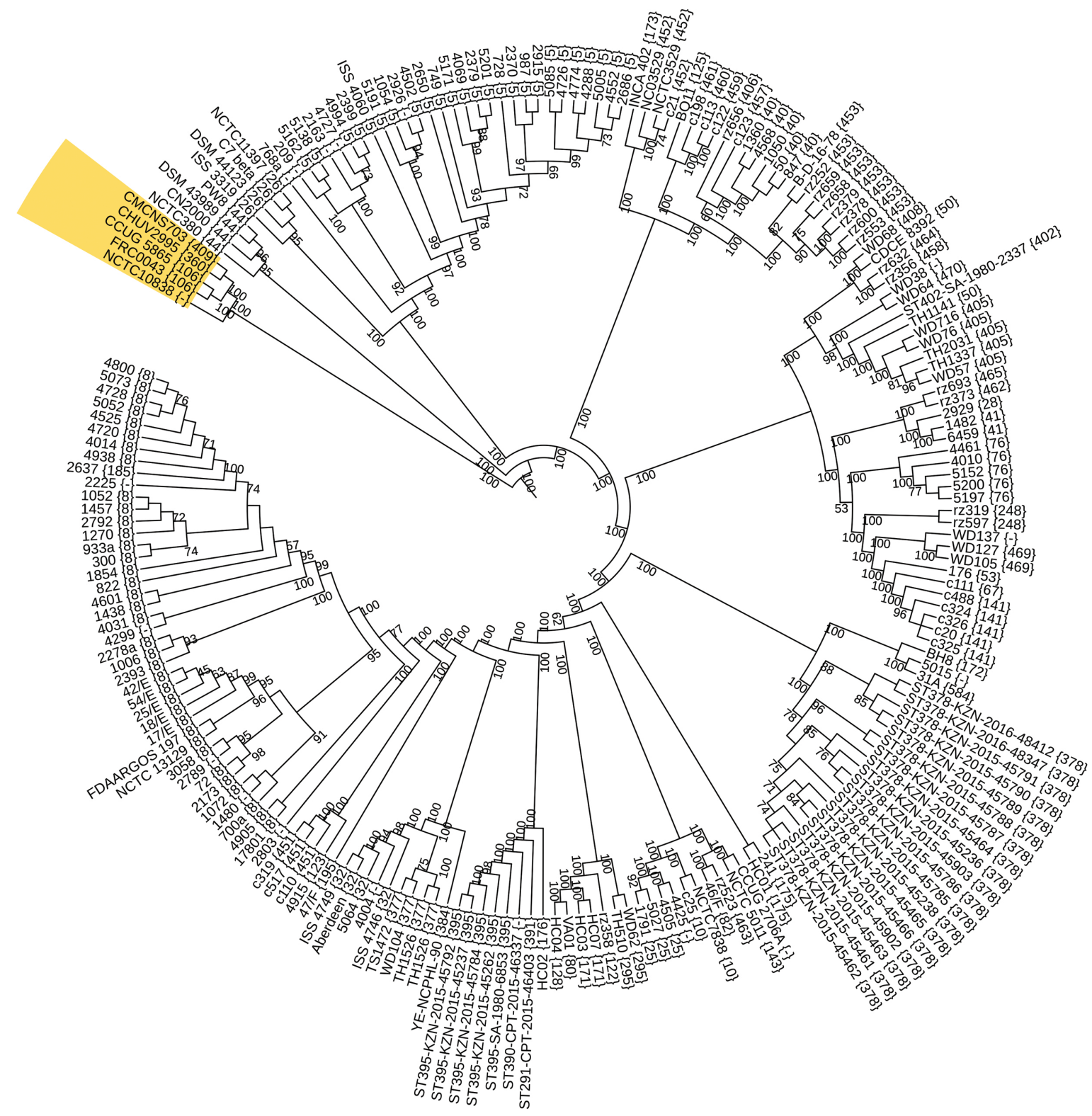

Рис. 1. Филогенетическое древо, построенное на основе штаммов C. diphtheriae с публично доступными просеквенированными геномами. Длины ветвей и использованный для укоренения геном C. ulcerans BR-AD22 не отображены. Числа на ветвях отображают уровни локальной поддержки. Серым цветом обозначены штаммы C. diphtheriae subsp. lausannense. Числа в скобках обозначают предсказанные сиквенс-типы по номенклатуре РubMLST (прочерки соответствуют неописанным сиквенс-типам) 
из 202, относящихся к данному подвиду в исследуемой выборке) были подобраны праймеры narG_F: CTGACCACT GGGGCGAGG $и$ narG_R: GAGTTGTCATAACGCCACTG (ожидаемая длина продукта - 691 пн).

Проведение ПЦР с праймерами для амплификации фрагментов генов pts/ и narG (рис. 3) показало, что в образцах, содержащих ДНК изучаемых штаммов В-8759 и B-8760, присутствует ген pts/ и отсутствует ген narG, в то время как с классическими штаммами C. diphtheriae наблюдалась обратная картина. Не было случаев, когда у одного штамма обнаруживали одновременно два локуса или ни одного локуса.

В совокупности с данными биохимической идентификации это позволило нам сделать заключение, что изученные штаммы C. diphtheriae относятся к виду C. diphtheriae subsp. lausannense. Дополнительно этот вывод был подтвержден тем, что выделенные штаммы принадлежали к сиквенс-типу ST199, входящему в клональный комплекс, предположительно характерный для представителей данного подвида (см. рис. 2). Еще одним подтверждением служила последовательность гена $d t x R$, которая совпадала с последовательностями, имеющимися В геномах представителей подвида lausannense.

Учитывая, что у штаммов C. diphtheriae subsp. lausannense присутствует ген, кодирующий фосфоенолпируват-белок фосфотрансферазы, входящей в фосфотрансферазную систему, для, вероятно, N-ацетилглюкозамина, мы провели эксперименты по оценке фенотипического проявления этого гена. Эксперименты показали, что оба изученных штамма, отнесенных к C. diphtheriae subsp. lausannense, сбраживали $\mathrm{N}$-ацетилглюкозамин в рамках предложенной системы, в отличие от штаммов C. diphtheriae subsp. diphtheriae (рис. 4).

Изученные штаммы, определенные по результатам данного исследования как C. diphtheriae subsp. lausannense, депонированы в Государственную коллекцию патогенных микроорганизмов «ГКПМ-Оболенск».

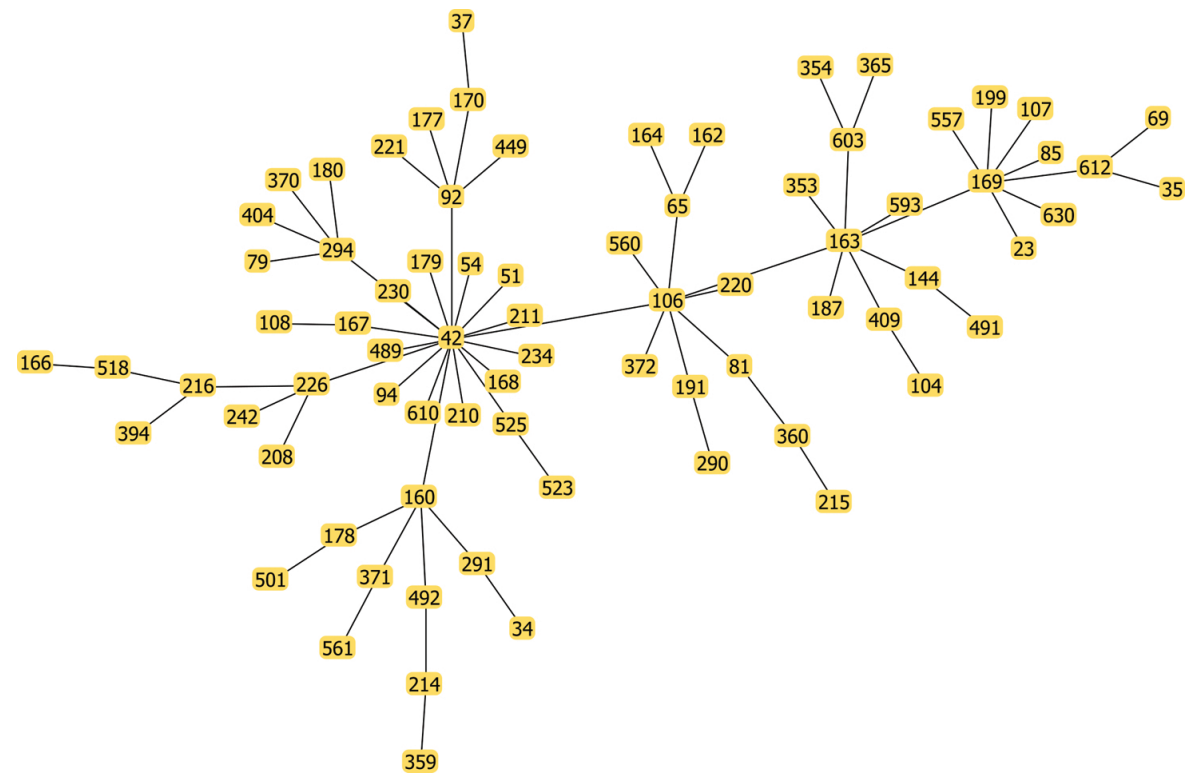

Рис. 2. Клональный комплекс, реконструированный на основе данных PubMLST, к которому относятся штаммы подвида lausannепsе с публично доступными просеквенированными геномами

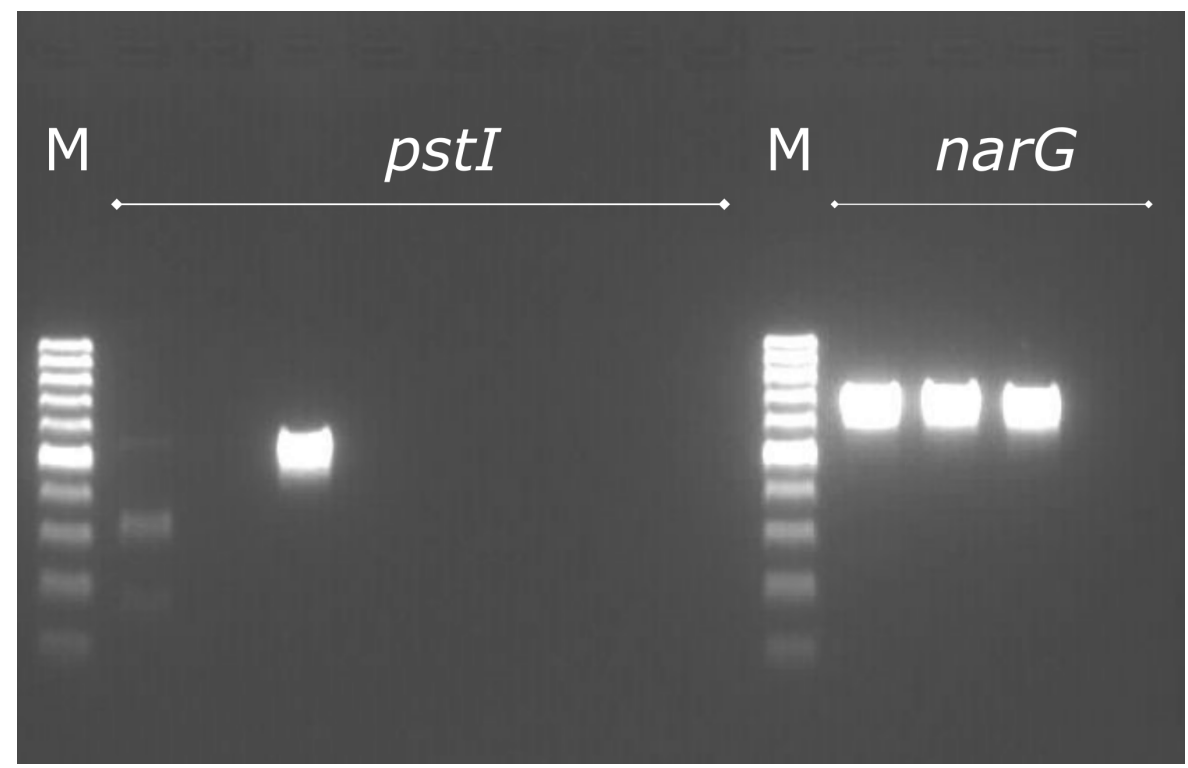

Рис. 3. Пример гель-электросореза результатов ПЦР с праймерами pts/_F — pts/_R и narG_F _ narG_R. M — маркер молекулярных весов ДНК GeneRuler 100 bp DNA Ladder (Thermo Fisher Scientific; CШA) 


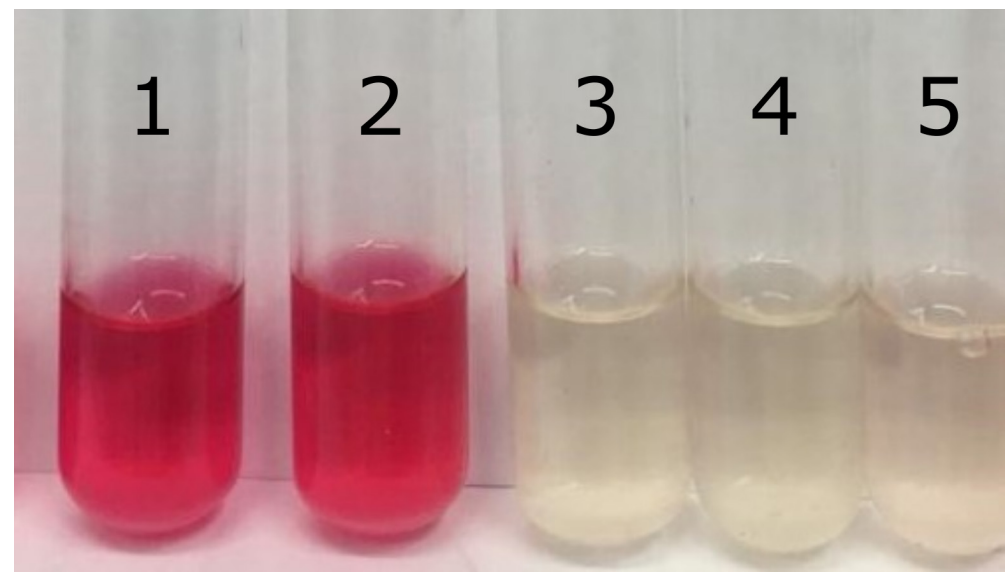

Рис. 4. Сахаролитическая активность штаммов C. diphtheriae subsp. lausannense - способность сбраживать N-ацетилглюкозамин. Положительный результат соответствует окрашиванию среды в малиновый цвет. 1, 2 - выделенные штаммы C. diphtheriae subsp. lausannense; 3 - штамм C. diphtheriae subsp. diphtheriae биовара gravis; 4 - штамм C. diphtheriae subsp. diphtheriae биовара mitis; 5 — отрицательный контроль

\section{ОБСУЖДЕНИЕ РЕЗУЛЬТАТОВ}

Нам удалось на территории России идентифицировать нетоксигенные штаммы C. diphtheriae subsp. lausannense, что наряду с данными зарубежных исследований $[14,22]$ свидетельствует об их повсеместной циркуляции. Выделенные штаммы принадлежали к сиквенс-типу ST199, входящему в кластер lineage-2, характерный для подвида lausannense, и несли последовательность гена $d t x R$, характерную для представителей данного подвида. Анализ групп ортологов позволил нам установить существование локусов, специсичных для подвидов C. diphtheriae: региона, содержащего гены $\mathrm{N}$-ацетилглюкозаминфосфотрансферазной системы, - для подвида lausannense и локус, кодирующий синтез субъединиц нитратредуктазы, для подвида diphtheriae. Последнее подтверждает более ранние геномные исследования подвида lausannense [15] и исследования биохимических свойств биовара belfantii $[9,10]$. Сконструированные под эти гены праймеры и проведение ПЦР позволили нам подтвердить идентификацию исследуемых двух штаммов как $C$. diphtheriae subsp. lausannense.

\section{ВЫВОДЫ}

В результате данного исследования на территории России были идентифицированы нетоксигенные штаммы C. diphtheriae subsp. lausannense. Полученные результаты расширяют представления о биологическом разнообразии вида C. diphtheriae и свидетельствуют о необходимости проведения исследований по оценке распространенности этих микроорганизмов на территории нашей страны и их патогенного потенциала.

\section{Литература}

1. World Health Organization. Diphtheria reported cases. Available from: http://apps.who.int/immunization_monitoring/ globalsummary/timeseries/tsincidencediphtheria.html.

2. Якимова Т. Н., Маркина С. С., Максимова Н. М. Дифтерия сегодня. ЗНиСО. 2013; 249 (12): 18-9.

3. О заболеваемости дифтерией и состоянии антитоксического противодифтерийного иммунитета населения России. Инсормационное письмо № 02/14390-2019-27 от 10.10.2019. Федеральная служба по надзору в сфере защиты прав потребителей и благополучия человека (Роспотребнадзор). Russian.

4. Romney MG, Roscoe DL, Bernard K, Lai S, Efstratiou A, Clarke AM. Emergence of an invasive clone of nontoxigenic Corynebacterium diphtheriae in the urban poor population of Vancouver, Canada. J Clin Microbiol. 2006 May; 44 (5): 1625-9.

5. Hirata J, Pereira GA, Filardy AA, Gomes DLR, Damasco PV Rosa ACP, et al. Potential pathogenic role of aggregativeadhering Corynebacterium diphtheriae of different clonal groups in endocarditis. Brazilian J Med Biol Res. 2008; 41 (11): 986-91.

6. Gubler J, Huber-Schneider C, Gruner E, Altwegg M. An Outbreak of Nontoxigenic Corynebacterium diphtheriae Infection: Single Bacterial Clone Causing Invasive Infection Among Swiss Drug Users. Clin Infect Dis. 1998 Nov; 27 (5): 1295-8.

7. FitzGerald RP, Rosser AJ, Perera DN. Non-toxigenic penicillinresistant cutaneous $\mathrm{C}$. diphtheriae infection: $\mathrm{A}$ case report and review of the literature. J Infect Public Health. 2015 Jan 1; 8 (1): 98-100.

8. Edwards B, Hunt AC, Hoskisson PA. Recent cases of non-

toxigenic Corynebacterium diphtheriae in Scotland: Justification for continued surveillance. Journal of Medical Microbiology. 2011; (60): 561-2.

9. Funke G, Von Graevenitz A, Clarridge JE, Bernard KA. Clinical microbiology of Coryneform bacteria. Clinical Microbiology Reviews. 1997; (10): 125-59.

10. Bernard KA, Funke G. Corynebacterium. In: Bergey's Manual of Systematics of Archaea and Bacteria. Chichester, UK: John Wiley \& Sons, Ltd, 2015; p. 1-70.

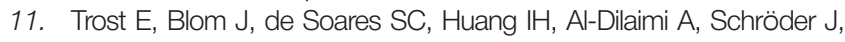
et al. Pangenomic study of Corynebacterium diphtheriae that provides insights into the genomic diversity of pathogenic isolates from cases of classical diphtheria, endocarditis, and pneumonia. J Bacteriol. 2012; 194 (12): 3199-215.

12. Sangal V, Burkovski A, Hunt AC, Edwards B, Blom J, Hoskisson PA. A lack of genetic basis for biovar differentiation in clinically important Corynebacterium diphtheriae from whole genome sequencing. Infect Genet Evol. 2014; 21 (November): 54-7.

13. Sangal V, Hoskisson PA. Evolution, epidemiology and diversity of Corynebacterium diphtheriae: New perspectives on an old foe. Infect Genet Evol. 2016; (43): 364-70.

14. Bolt F, Cassiday P, Tondella ML, DeZoysa A, Efstratiou A, Sing A, et al. Multilocus Sequence Typing Identifies Evidence for Recombination and Two Distinct Lineages of Corynebacterium diphtheriae. J Clin Microbiol. 2010; 48 (11): 4177-85.

15. Tagini F, Pillonel T, Croxatto A, Bertelli C, Koutsokera A, Lovis A, et al. Distinct genomic features characterize two clades of Corynebacterium diphtheriae: Proposal of Corynebacterium 
diphtheriae Subsp. diphtheriae Subsp. nov. and Corynebacterium diphtheriae Subsp. lausannense Subsp. nov. Front Microbiol. 2018 Aug 17; (9): 1743.

16. Li L, Stoeckert CJ, Roos DS. OrthoMCL: identification of ortholog groups for eukaryotic genomes. Genome Res. 2003; 13 (9): 2178-89.

17. Edgar RC. MUSCLE: multiple sequence alignment with high accuracy and high throughput. Nucleic Acids Res. 2004; 32 (5): 1792-7.

18. Price MN, Dehal PS, Arkin AP. FastTree 2 - Approximately maximum-likelihood trees for large alignments. PLoS One. 2010 Mar 10; 5 (3).

19. Nascimento M, Sousa A, Ramirez M, Francisco AP, Carriço JA, Vaz C. PHYLOViZ 2.0: Providing scalable data integration

\section{References}

1. World Health Organization. Diphtheria reported cases. Available from: http://apps.who.int/immunization_monitoring/ globalsummary/timeseries/tsincidencediphtheria.html.

2. Yakimova TN, Markina SS, Maksimova NM. Difteriya segodnya ZNiSO. 2013; 249 (12): 18-9. Russian.

3. O zabolevaemosti difteriey i sostoyanii antitoksicheskogo protivodifteriynogo immuniteta naseleniya Rossii. Information letter № 02/14390-2019-27 from 10.10.2019. Federal Service for Surveillance on Consumer Rights Protection and Human Wellbeing (Rospotrebnadzor). Russian.

4. Romney MG, Roscoe DL, Bernard K, Lai S, Efstratiou A, Clarke AM. Emergence of an invasive clone of nontoxigenic Corynebacterium diphtheriae in the urban poor population of Vancouver, Canada. J Clin Microbiol. 2006 May; 44 (5): 1625-9.

5. Hirata J, Pereira GA, Filardy AA, Gomes DLR, Damasco PV Rosa ACP, et al. Potential pathogenic role of aggregativeadhering Corynebacterium diphtheriae of different clonal groups in endocarditis. Brazilian J Med Biol Res. 2008; 41 (11): 986-91.

6. Gubler J, Huber-Schneider C, Gruner E, Altwegg M. An Outbreak of Nontoxigenic Corynebacterium diphtheriae Infection: Single Bacterial Clone Causing Invasive Infection Among Swiss Drug Users. Clin Infect Dis. 1998 Nov; 27 (5): 1295-8.

7. FitzGerald RP, Rosser AJ, Perera DN. Non-toxigenic penicillinresistant cutaneous $C$. diphtheriae infection: A case report and review of the literature. J Infect Public Health. 2015 Jan 1; 8 (1): 98-100.

8. Edwards B, Hunt AC, Hoskisson PA. Recent cases of nontoxigenic Corynebacterium diphtheriae in Scotland: Justification for continued surveillance. Journal of Medical Microbiology. 2011; (60): 561-2.

9. Funke G, Von Graevenitz A, Clarridge JE, Bernard KA. Clinical microbiology of Coryneform bacteria. Clinical Microbiology Reviews. 1997; (10): 125-59.

10. Bernard KA, Funke G. Corynebacterium. In: Bergey's Manual of Systematics of Archaea and Bacteria. Chichester, UK: John Wiley \& Sons, Ltd, 2015; p. 1-70.

11. Trost E, Blom J, de Soares SC, Huang $\mathbb{H}$, Al-Dilaimi A, Schröder J, et al. Pangenomic study of Corynebacterium diphtheriae that provides insights into the genomic diversity of pathogenic isolates from cases of classical diphtheria, endocarditis, and pneumonia. J Bacteriol. 2012; 194 (12): 3199-215.

12. Sangal V, Burkovski A, Hunt AC, Edwards B, Blom J, Hoskisson PA. A and visualization for multiple phylogenetic inference methods. Bioinformatics. 2017; 33 (1): 128-9.

20. Nakao H, Mazurova IK, Glushkevich T, Popovic T. Analysis of heterogeneity of Corynebacterium diphtheriae toxin gene, tox, and its regulatory element, $d t x R$, by direct sequencing. Res Microbiol. 1997; 148 (1): 45-54.

21. Chagina IA, Perevarova YuS, Perevarov W, Chaplin AV, Borisova OYu, Kafarskaya LI, et al. Polymorphism of the dtxR gene in the currently existing strains of Corynebacterium diphtheriae. Bulletin of RSMU. 2017; (1): 31-37.

22. Farfour E, Badell E, Dinu S, Guillot S, Guiso N. Microbiological changes and diversity in autochthonous non-toxigenic Corynebacterium diphtheriae isolated in France. Clin Microbiol Infect. 2013; 19 (10): 980-7.

lack of genetic basis for biovar differentiation in clinically important Corynebacterium diphtheriae from whole genome sequencing. Infect Genet Evol. 2014; 21 (November): 54-7.

13. Sangal V, Hoskisson PA. Evolution, epidemiology and diversity of Corynebacterium diphtheriae: New perspectives on an old foe. Infect Genet Evol. 2016; (43): 364-70.

14. Bolt F, Cassiday P, Tondella ML, DeZoysa A, Efstratiou A, Sing A, et al. Multilocus Sequence Typing Identifies Evidence for Recombination and Two Distinct Lineages of Corynebacterium diphtheriae. J Clin Microbiol. 2010; 48 (11): 4177-85.

15. Tagini F, Pillonel T, Croxatto A, Bertelli C, Koutsokera A, Lovis A, et al. Distinct genomic features characterize two clades of Corynebacterium diphtheriae: Proposal of Corynebacterium diphtheriae Subsp. diphtheriae Subsp. nov. and Corynebacterium diphtheriae Subsp. lausannense Subsp. nov. Front Microbiol. 2018 Aug 17; (9): 1743.

16. Li L, Stoeckert CJ, Roos DS. OrthoMCL: identification of ortholog groups for eukaryotic genomes. Genome Res. 2003; 13 (9): 2178-89.

17. Edgar RC. MUSCLE: multiple sequence alignment with high accuracy and high throughput. Nucleic Acids Res. 2004; 32 (5): $1792-7$.

18. Price MN, Dehal PS, Arkin AP. FastTree 2 - Approximately maximum-likelihood trees for large alignments. PLoS One. 2010 Mar 10; 5 (3).

19. Nascimento M, Sousa A, Ramirez M, Francisco AP, Carriço JA, Vaz C. PHYLOViZ 2.0: Providing scalable data integration and visualization for multiple phylogenetic inference methods. Bioinformatics. 2017; 33 (1): 128-9.

20. Nakao H, Mazurova IK, Glushkevich T, Popovic T. Analysis of heterogeneity of Corynebacterium diphtheriae toxin gene, tox, and its regulatory element, $\mathrm{dtxR}$, by direct sequencing. Res Microbiol. 1997; 148 (1): 45-54.

21. Chagina IA, Perevarova YuS, Perevarov W, Chaplin AV, Borisova OYu, Kafarskaya LI, et al. Polymorphism of the $\mathrm{dtxR}$ gene in the currently existing strains of Corynebacterium diphtheriae. Bulletin of RSMU. 2017; (1): 31-37.

22. Farfour E, Badell E, Dinu S, Guillot S, Guiso N. Microbiological changes and diversity in autochthonous non-toxigenic Corynebacterium diphtheriae isolated in France. Clin Microbiol Infect. 2013; 19 (10): 980-7. 


\title{
СИНТЕЗ ЛИНОЛЕВОЙ КИСЛОТЫ, МЕЧЕННОЙ ${ }^{13} \mathrm{C} \mathrm{И}{ }^{14} \mathrm{C}$, ДЛЯ ПРОВЕДЕНИЯ ДИАГНОСТИЧЕСКИХ ДЫХАТЕЛЬНЫХ ТЕСТОВ ЗАБОЛЕВАНИЙ ГЕПАТОБИЛИАРНОЙ СИСТЕМЫ
}

Я. Я. Тыньо $₫$, Г. В. Морозова², Ю. К. Бирюкова А. Б. Шевелёв 3,6

${ }^{1}$ Российский государственный университет физической культуры, спорта, молодежи и туризма, Москва, Россия

2 Московская государственная академия ветеринарной медицины и биотехнологии имени К. И. Скрябина, Москва, Россия

${ }^{3}$ Институт общей генетики имени Н. И. Вавилова, Москва, Россия

${ }^{4}$ Первый Московский государственный медицинский университет имени И. М. Сеченова, Москва, Россия

${ }^{5}$ Национальный медицинский исследовательский центр онкологии имени Н. Н. Блохина, Москва, Россия

${ }^{6}$ Российский экономический университет имени Г. В. Плеханова, Москва, Россия

В настоящее время для диагностики заболеваний печени и билиарной системы требуется разработка простого неинвазивного теста с высокой чувствительностью и специфичностью. Соединения, меченные изотопом углерода, уже имеют широкое применение в диагностике различных заболеваний методами дыхательных тестов, безопасны и способны достоверно выявлять метаболические нарушения или дефицит специфичных ферментов в органах. Целью работы было получить линолевую кислоту, меченную ${ }^{13} \mathrm{C}$ и ${ }^{14} \mathrm{C}$, по степени очистки пригодную для проведения дыхательных тестов в целях диагностики заболеваний гепатобилиарной системы. В предложенном способе химический выход реакции синтеза ${ }^{13} \mathrm{C}$-линолевой кислоты по

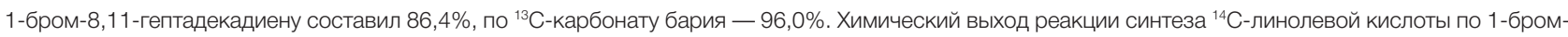

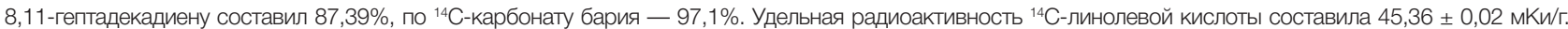
Радиохимический выход реакции - 96,0\%. Способ удобен для серийного выпуска готового продукта.

Ключевые слова: дыхательный тест, линолевая кислота, ${ }^{13} \mathrm{C},{ }^{14} \mathrm{C}$, гепатобилиарная система, заболевания печени

Вклад авторов: Я. Я. Тыньо - идея, общее руководство; Г. В. Морозова - синтез конечных соединений путем карбоксилирования реактива Гриньяра диоксидом ${ }^{13} \mathrm{C}$ и ${ }^{14} \mathrm{C}$, материальный баланс всей схемы синтеза; Ю. К. Бирюкова — ЯМР-анализ конечного продукта синтеза; Д. А. Сивохин - обзор литературы, подготовка рукописи к печати; Н. В. Позднякова - обзор литературы; М. В. Зылькова - определение уровня радиоактивности атомов углерода в исходных веществах, полупродуктах синтеза и конечных соединениях; Е. С. Богданова - расшифровка ЯмР-спектра конечных продуктов синтеза; М. С. Смирнова - определение температуры плавления конечного соединения; А. Б. Шевелёв - материально-техническое снабжение работы и обеспечение доступа к оборудованию, редактирование перевода рукописи.

$\checkmark$ Для корреспонденции: Ярослав Ярославович Тыньо Сиреневый бульвар, д. 4, г. Москва, 105122; yytynio@mail.ru

Статья получена: 31.03.2020 Статья принята к печати: 15.04.2020 Опубликована онлайн: 25.04.2020

DOI: $10.24075 /$ vrgmu.2020.022

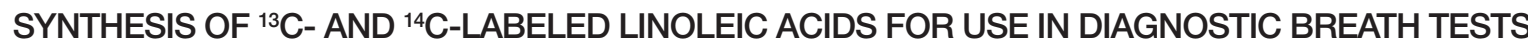 FOR HEPATOBILIARY SYSTEM DISORDERS}

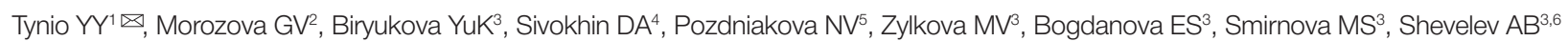 \\ ${ }^{1}$ Russian State University of Physical Education, Sport, Youth and Tourism, Moscow, Russia \\ 2 Skryabin Moscow State Academy of Veterinary Medicine and Biotechnology, Moscow, Russia \\ ${ }^{3}$ Vavilov Institute of General Genetics, Moscow, Russia \\ ${ }^{4}$ Sechenov First Moscow State Medical University, Moscow, Russia \\ ${ }^{5}$ Blokhin National Medical Research Center of Oncology, Moscow, Russia \\ ${ }^{6}$ Plekhanov Russian University of Economics, Moscow, Russia
}

\begin{abstract}
At present, there is a need for a simple, noninvasive, highly specific and sensitive diagnostic test for hepatobiliary system disorders. Compounds labeled with carbon isotopes are widely used in various diagnostic breath tests; they are safe and can reliably detect a metabolic disorder or enzyme deficiency. The aim of this study was to synthesize ${ }^{13} \mathrm{C}$ - and ${ }^{14} \mathrm{C}$-labeled linoleic acids suitable for use in hepatobiliary breath tests in terms of purity. In the synthesis of ${ }^{13} \mathrm{C}$-labeled linoleic acid, the chemical yield for 1 -bromo-8,11-heptadecadien was $86.4 \%$ and the chemical yield for barium carbonate- ${ }^{13} \mathrm{C}, 96.0 \%$. In the synthesis of ${ }^{14} \mathrm{C}$-labeled linoleic acid, the chemical yield for 1 -bromo-8,11-heptadecadien was $87.39 \%$; for barium carbonate- ${ }^{14} \mathrm{C}$ it was $97.1 \%$. The specific radioactivity of ${ }^{14} \mathrm{C}$-labeled linoleic acids was $45.36 \pm 0.02 \mathrm{mCi} / \mathrm{g}$. The radiochemical yield of the reaction was $96.0 \%$. The proposed method is suitable for batch production.
\end{abstract}

Keywords: breath test, linoleic acid, ${ }^{13} \mathrm{C},{ }^{14} \mathrm{C}$, hepatobiliary system, liver disease

Author contribution: Tynio YY conceived and supervised the study; Morozova GV synthesized the final product by carboxylation of the Grignard reagent with ${ }^{13} \mathrm{C}$ and ${ }^{14} \mathrm{C}$ dioxides, did preparative calculations; Biryukova YuK conducted NMR-analysis of the final product; Sivokhin DA analyzed the literature and wrote the manuscript; Pozdniakova NV analyzed the literature; Zylkova MV measured the radioactivity of carbon atoms in the reagents, intermediate and final products; Bogdanova ES analyzed the NMR spectra of the final products; Smirnova MS determined the melting point of the final products; Shevelev AB provided reagents and instrumentation and revised the manuscript.

$\triangle$ Correspondence should be addressed: Yaroslav Y. Tynio Sirenevyi bulvar, 4, Moscow, 105122; yytynio@mail.ru

Received: 31.03.2020 Accepted: 15.04.2020 Published online: 25.04.2020

DOI: $10.24075 /$ brsmu.2020.022 